\title{
GENERALIZAÇÃO DISCURSIVA E ENUNCIAÇÃO NAS CANTIGAS DE CONGADO EM MINAS GERAIS: UMA ABORDAGEM SEMIOLINGUÍSTICA
}

\author{
ELISSON FERREIRA MORATO ${ }^{1}$
}

Universidade Estadual de Minas Gerais - Campus Divinópolis

Avenida Paraná, 3001 - 35501-170 - Jardim Belvedere I, Divinópolis - MG - Brasil

\author{
elissonmorato@yahoo.com.br
}

\begin{abstract}
Resumo. Este trabalho estuda as generalizações discursivas nas cantigas de congado de Minas Gerais pela Análise do Discurso de linha francesa. A partir do conceito de generalização discursiva, desenvolvido por AliBouacha (1993, [2007] 2020) e Moirand (1990), e de competências linguageiras, estratégias discursivas e enunciação, da teoria Semiolinguística de Charaudeau (1983, [2000] 2020a, 2004a, 2004b, 2005a, 2005b, [2006] 2020b, 2008), entendemos que as generalizações discursivas seriam efeitos de sentido baseados na atribuição deste discurso a um metaenunciador, construindo um efeito de verdade universal. Esse procedimento contribui para que um conjunto de saberes configure a identidade de um grupo social fortemente identificado com as tradições culturais afrobrasileiras.
\end{abstract}

Palavras-chave: generalização discursiva; enunciação; cantigas de congado; Análise do Discurso.

\begin{abstract}
This paper studies the discursive generalizations in the congado songs of the Brazilian state of Minas Gerais through the Discourse Analysis of French line. From the concept of discursive generalization, developed by Ali-Bouacha (1993, [2007] 2020) and by Moirand (1990), and throught the concepts of language competences, discursive strategies and enunciation, from the Semiolinguistic theory developed by Charaudeau (1983, [2000] $2020 a, 2004 a, 2004 b, 2005 a, 2005 b$, [2006] 2020b, 2008), we understand that discursive generalizations would be effects of meaning based on the assignation of this discourse to a meta-enunciator, building effects of universal truth. This procedure contributes for that a knowledge set forms the identity of a social group deeply identified with the Afro-Brazilian cultural traditions.
\end{abstract}

Keywords: discursive generalization; enunciation; congado songs; Discourse Analysis.

\footnotetext{
${ }^{1}$ Docente nos cursos de Graduação em Letras e Pedagogia da Universidade Estadual de Minas Gerais, Campus Divinópolis.
} 


\section{INTRODUÇÃO}

O discurso é norteador e, ao mesmo tempo, revelador das práticas sociais, que envolvem a construção, a manutenção e a circulação de saberes. Através do exame do discurso e de suas condições ideológicas e materiais de produção, que regem o sujeito e definem seu dizer, se depreende o conjunto de representações que os sujeitos fazem do mundo como uma forma de conhecê-lo e explicá-lo. Dentre esses saberes de mundo, podemos citar formas de explicação através das quais os sujeitos se posicionam em sua enunciação de modo que seu discurso se assemelhe a uma voz única formada pela voz de todos: uma enunciação em uníssono. Esses discursos podem ser observados em vários grupos ou segmentos sociais, e se manifestam de maneira relevante em determinadas manifestações da cultura popular afro-brasileira, dentre as quais o congado.

Esses discursos, oriundos de práticas sociais fortemente relacionadas ao folclore e/ou à cultura popular, parecem despertar menor atenção devido a pouca repercussão social que provocam. A esse respeito, Maingueneau (2008, p. 199) exemplifica que "muitos analistas do discurso preferem trabalhar com textos ligados a interesses sociais imediatos", já que muitos textos "mantêm com a realidade social muito mais indireta do que a encontrada em textos de outros discursos" (MAINGUENEAU, 2008, p. 199). Maingueneau (2015, p. 95) acrescenta que o gênero de discurso exerce um tipo de coerção sobre o analista, de modo que, por exemplo, ao preterir os discursos políticos e midiáticos, o analista exemplifica uma desigualdade entre discursos dominantes e dominados.

Trata-se de discursos alheios a grandes questões sociais e que trazem, em si, a manutenção de um mundo de crenças e valores de um grupo social muito específico. Essa manifestação é conhecida em Minas Gerais como congado, ou reinado, e seu estudo rende subsídios para a Análise do Discurso na medida em que outros corpora suscitam problemáticas diferentes através das quais se pode mobilizar a teoria de maneira a verificar seu alcance com mais propriedade.

Nessa perspectiva, estudamos o funcionamento das generalizações discursivas nas cantigas de congado através do conceito de generalização discursiva, de Ali-Bouacha (1993, [2007] 2020), Moirand (1990), e meta-enunciação de Chabrol (2004), e da teoria Semiolinguística de Charaudeau (1983, [2000] 2020a, [2006] 2020b, 2004a, 2004b, 2005a, 2005b, 2008), através dos conceitos de competências linguageiras, estratégias de discursos e enunciação. As generalizações discursivas, tomadas a partir da conceituação de Ali-Bouacha (1993, [2007] 2020), são fenômenos relacionados à enunciação, razão pela qual mobilizamos a Semiolinguística, que nos oferece um amplo instrumental teórico com o qual podemos entender a construção desse efeito de sentido pelo enunciador.

Começamos esta abordagem pela discussão sobre generalização discursiva, seguindo-se uma abordagem da relação entre a Semiolinguística e a noção de generalização discursiva. Para melhor compreender o contexto do discurso do congado, recorremos ao trabalho de Pereira; Gomes (2000), Garone ([2008] 2020) e Silva ([2015] 2020). Também recorremos a Rios (2006) e Magalhães (2006), autores que nos auxiliam a compreender o significado das práticas discursivas presentes nas festividades de congado. 
As cantigas que formam o corpus deste estudo foram retiradas do $\mathrm{CD}$ duplo $O$ reinado do Rosário em Itapecerica, que traz um encarte, do qual foram copiados os trechos citados na análise, com a transcrição de um amplo repertório de cantigas recorrentes nas festividades de congado da região centro-oeste de Minas Gerais e adjacências. A duração dessas cantigas é extremamente variável em ambos os CDs, o que influencia a quantidade de cantigas disponibilizadas em cada um. O primeiro CD é intitulado Da festa e comporta 24 faixas, sendo a menor com 28 segundos de duração e a maior 4 minutos e 51 segundos. O segundo CD, intitulado Dos Mistérios, traz 18 faixas, sendo a maior com duração de 11 minutos e 30 segundos e a menor 1 minuto e 11 segundos. O CD (duplo) foi produzido pela Associação do Reinado do Rosário de Itapecerica (ARRI) (2006).

As gravações ocorreram durante o período da festa de Reinado que se realiza anualmente na cidade, em agosto. Na ocasião, cada guarda foi convidada a apresentar uma ou mais cantigas que seriam incluídas no $\mathrm{CD}$. Os registros foram feitos ao ar livre na Fazenda Palestina, sítio histórico localizado próximo à cidade de Itapecerica (ARRI, 2006).

\section{GENERALIZAÇÕES DISCURSIVAS: O ENUNCIADO POR TODOS}

Segundo Ali-Bouacha (1993, [2007] 2020), as generalizações discursivas são enunciados considerados como incontestáveis e que invocam uma forma do enunciador se posicionar no discurso que "é construído para a adesão do outro"” (ALI-BOUACHA, 1993, p. 281), sendo esse um "enunciado para ser repetido" (ALI-BOUACHA, 1993, p. 281). O autor também aponta que as generalizações discursivas são "formas pelas quais um enunciador/locutor é levado a proferir um enunciado sempre verdadeiro conforme a intenção de um co-enunciador/alocutário ${ }^{4}$ " (ALI-BOUACHA, [2007] 2020, p. 6) de modo a produzir discursos sintéticos e codificados ritualisticamente na situação de comunicação para asseverar um conhecimento, ou uma crença, que se propõe como uma verdade.

Haveria, assim, em um enunciado generalizante, uma estreita relação entre a maneira como o sujeito do discurso enuncia e os efeitos de sentido, já que esse enunciador "não remete a um discurso sem sujeitos, mas ao contrário, a um discurso de todos os sujeitos" (ALI-BOUACHA, [2007] 2020, p. 7). O que, segundo Moirand (1990, p. 76), faz com que esses enunciados traduzam uma experiência individual como uma verdade que se propõe como universal. Assim, ao servirem de "garantias de supostas verdade e de veracidade dispostas por um meta-enunciador" (CHABROL, 2004, p. 43), as generalizações se colocam como enunciados produzidos por todos os enunciadores e, ao mesmo tempo, por nenhum individualmente, caracterizando o efeito de meta-enunciação.

\footnotetext{
${ }^{2}$ Frase no idioma original (tradução livre dos autores): “est construit pour emporter l'adhésion de l'autre".

${ }^{3}$ Frase no idioma original (tradução livre dos autores): "est énoncé pour être répété".

${ }^{4}$ Frase no idioma original (tradução livre dos autores): "formes par lesquelles un énonciateur/locuteur est amené à proférer un énoncé "toujours-vrai” à l'intention d'un co-énonciateur/allocutaire”.

${ }^{5}$ Frase no idioma original (tradução livre dos autores): "Il ne renvoie pas à un discours sans sujets mais au contraire à un discours de tous les sujets".

${ }^{6}$ Frase no idioma original (tradução livre dos autores): “garanties de vérité et de véracité supposées portées par un 'méta-énunciateur".
} 


\section{GENERALIZAÇÕES DISCURSIVAS NUMA PERSPECTIVA SEMIOLINGUÍSTICA}

Na perspectiva da Semiolinguística, não se pode separar a produção discursiva do sujeito que a opera, e nem o sujeito individual da coletividade em que o discurso é construído: "pois a linguagem está no coração da construção tanto individual quanto coletiva do sujeito "' (CHARAUDEAU, [2006] 2020, p. 1). Nesse prospecto, a construção do discurso e de sua significação leva em conta as competências linguageiras que o sujeito deve dominar (CHARAUDEAU, [2006] 2020, p. 2) e que orientam a construção dos sentidos do discurso.

A competência situacional (cf. CHARAUDEAU, [2006] 2020, p. 2) requer do sujeito uma aptidão para construir seu discurso face à identidade dos parceiros da troca comunicacional, a finalidade dessa interação, o conteúdo do discurso e as circunstâncias materiais da comunicação. A competência discursiva (cf. CHARAUDEAU, [2006] 2020, p. 2) requer a aptidão para reconhecer os procedimentos enunciativos da situação de comunicação, e a competência semântica diz respeito à aptidão para reconhecer e partilhar saberes necessários ao funcionamento dos signos presentes na intercomunicação (cf. CHARAUDEAU, [2006] 2020, p. 2).

Por sua vez, essa significação também se baseia em um conjunto de imaginários sócio-culturais, ou representações (cf. CHARAUDEAU, [2006] 2020, p. 4), que dão sustentação a esses sentidos. Assim, é preciso que o discurso faça sentido para os interlocutores e que estes tomem os sentidos dentro de representações sócio-culturais, razão pela qual os sentidos funcionam para um grupo e não para outro. E a relação entre competências e imaginários remete a um meta-enunciador e às seguintes questões (cf. CHARAUDEAU, 2005, p. 1): em nome de quem fala o sujeito? Como o sujeito alega seu direito à fala? Desse modo, os efeitos de sentido decorrentes do discurso estabelecem um acordo a partir de um imaginário segundo o qual o grupo é herdeiro dessa significação. $O$ que pode ser melhor compreendido através do conceito de enunciação da Semiolinguística.

Para Charaudeau (1983, p. 40), a enunciação é a encenação do ato de linguagem: o dizer dentro de um papel e de um contexto social de troca linguageira. É o ato no qual o sujeito falante se reveste de uma máscara com a qual representa um papel social a partir do qual, pelo uso da linguagem, ele construirá sentidos em seu discurso. Essa encenação linguageira, por sua vez, é dada por um conjunto de restrições que, à maneira de um contrato, estabelece o que e para quem enunciar, com que propósito, e com qual dispositivo material (impresso, digital, oral, televisivo) enunciar. Assim, a enunciação envolve a colocação do sujeito na e pela linguagem através do exercício de um papel social pelo qual este representa a si e ao interlocutor: "o sentido está voltado, antes de tudo, para os parceiros do ato de linguagem; ele determina o modo de existência dos sujeitos falantes e, ao mesmo tempo, constrói representações sobre o mundo" (grifos do autor) (CHARAUDEAU, 2008, p. 12). Na enunciação se constrói a significação do discurso, ou se instituem os traços pelos quais esse sentido será co-construído pelo interlocutor.

\footnotetext{
${ }^{7}$ Frase no idioma original (tradução livre dos autores): "car le langage est au coeur de la construction aussi bien individuelle que collective du sujet".
} 
A enunciação, nessa perspectiva, é a "ação de seres psicossociais que são testemunhas, mais ou menos conscientes, das práticas sociais e das representações imaginárias da comunidade a qual pertencem" (CHARAUDEAU, 2008, p. 21). Esses sujeitos, na enunciação, se desdobram, de acordo com Charaudeau (2008), em representações do dizer. Assim, o Sujeito Comunicante, ser social que se desdobra em seu discurso, em um Sujeito Enunciador, projeta uma hipótese de saber sobre seu interlocutor, representado pelo Sujeito Destinatário, o qual, por sua vez, constitui o desdobramento do Sujeito Interpretante. $O$ que é ilustrado no esquema enunciativo proposto por Charaudeau (2008, p. 21):

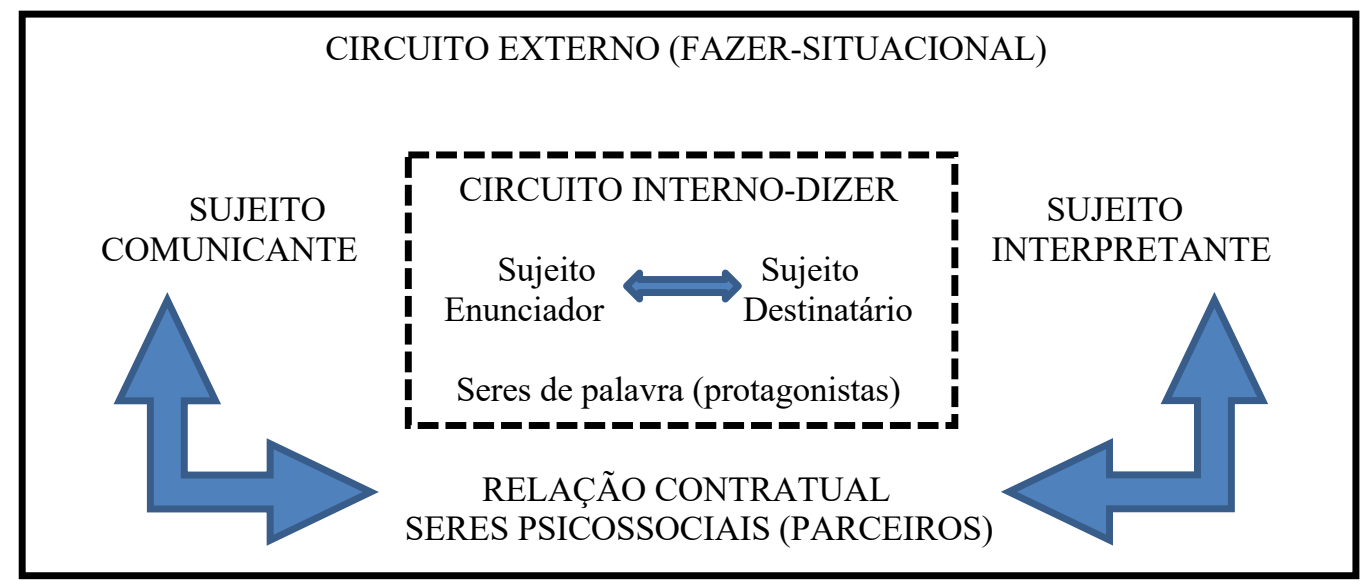

\section{Esquema 1. Quadro comunicacional da Semiolinguística de Charaudeau.}

Fonte. Charaudeau (2008, p. 21).

No esquema apresentado ${ }^{8}$, o Sujeito Enunciador, ser constituído na e pela linguagem, representa o desdobramento do Sujeito Comunicante, ser social, atuante em um universo de fazeres. O Sujeito Destinatário, presente no circuito interno desse quadro de comunicação, é a projeção de uma hipótese de saber construída pelo Sujeito Enunciador em relação ao Sujeito Interpretante, que também representa um fazer social e que pode ou não corresponder à hipótese construída pelo Sujeito Comunicante. Se a enunciação evoca o desdobramento do Sujeito Comunicante em Enunciador que credita seu dizer a um meta-enunciador, conforme a terminologia de Chabrol (2004).

A meta-enunciação, em termos semiolinguísticos poderia ser entendida como um discurso construído pelo enunciador, mas creditado a um terceiro enunciador: um enunciador plural formado por todos os enunciadores. No esquema seguinte (Esquema 1), procuramos demonstrar o funcionamento dessa meta-enunciação como estratégia de discurso mobilizada pelo Sujeito Comunicante, que se desdobra, no ato enunciativo, em um Sujeito Enunciador.

\footnotetext{
${ }^{8}$ Herdeiro da teoria de Pêcheux, Charaudeau traz em seu esquema uma relação interdiscursiva com a noção de formações imaginárias daquele autor. Entretanto, essa relação não será explorada por não condizer com os objetivos e com o enquadramento teórico deste artigo.
} 


\section{Meta-enunciador \\ (estratégia de discurso) \\ Sujeito Comunicante

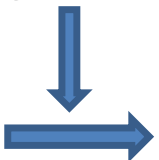 \\ Sujeito Enunciador}

\section{Esquema 2. O efeito de meta-enunciação como estratégia de discurso. \\ Fonte. Elaborado pelo autor.}

Esse meta-enunciador seria então o conjunto de mediações que permitem a esses interlocutores se entenderem e interagirem:

como dois indivíduos poderiam se relacionar, como poderiam eles se compreender se não existisse a mediação das representações comuns? Qual é esta mediação senão uma 'instância terceira'?'. (CHARAUDEAU, 2005b, p. 50)

O meta-enunciador, assim, é fundamental às generalizações, posto que ele sustenta o efeito de universalidade e veracidade desse discurso. De modo que a metaenunciação, assim, poderia ser entendida como uma estratégia discursiva mobilizada pelo sujeito.

O efeito de universalidade incontestável das generalizações discursivas é mantido pela coletividade que se enquadra, pelas competências linguageiras, em uma troca comunicacional, de modo que as generalizações funcionam em um conjunto de imaginários sócio-culturais que estabelece papéis aos sujeitos e maneiras de significar esse discurso. As generalizações também fazem com que o(s) interlocutor(es) partilhe(m) o que podemos chamar, neste artigo, de um quadro de pensamentos, graças às estratégias, como as de legitimação e credibilidade, a que recorre o enunciador.

A estratégia de legitimação outorga ao sujeito uma posição de autoridade que o possibilita enunciar. Há, então, uma autoridade institucional, "fundada pelo estatuto do sujeito que lhe confere autoridade de saber" (CHARAUDEAU, 2004a, p. 295) e uma autoridade pessoal, "fundada na atividade de persuasão e de sedução do sujeito que lhe dá uma autoridade de fato" (CHARAUDEAU, 2004a, p. 295). A estratégia de legitimação, empregada de maneira eficaz no discurso, confere ao sujeito uma aura de respeitabilidade em relação aos demais interlocutores.

Já a estratégia de credibilidade (CHARAUDEAU, 2004b, p. 143) visa levar o sujeito a ser reconhecido em uma posição de verdade. No caso, colocando-se em uma posição de neutralidade enunciativa, o sujeito exime-se de opinião, apagando os traços de avaliação pessoal em seu discurso. Outra forma de atestar essa posição de verdade é atribuir a própria enunciação a um meta-enunciador.

\footnotetext{
${ }^{9}$ Frase no idioma original (tradução livre dos autores): “comment deux individus pourraient-ils échanger, comment pourraient-ils se comprendre si n'existait la médiation des représentations communes? Quelle est cette médiation sinon une "instance-tiers" ?".
} 
Mas, vejamos a seguir como esses postulados funcionam em relação às cantigas de congado.

\section{O CONGADO E SUAS CANTIGAS}

Congado, ou reinado, são nomes genéricos com que se denominam certas festividades afrodescendentes que ocorrem especialmente em Minas Gerais, sendo encontradas também no sudeste de Goiás. A palavra reinado se deve a eleição e coroação em cada festa de um rei e de uma rainha simbólicos que representam Nossa Senhora do Rosário, protetora dos negros. Já a palavra congado é de origem incerta, podendo ser derivada de congos, nome pelo qual eram denominadas indistintamente as danças e/ou festas dos negros, segundo o termo usado na época, durante o Brasil colônia (cf. MAGALHÃES, 2006).

As festas ocorrem em épocas diversas durante todo o ano, se estendendo de maio a novembro, sendo presididas por santos padroeiros, especialmente Nossa senhora do Rosário, São Benedito e Santa Efigênia. O início do festejo ocorre com o levantamento do mastro(s) tendo a bandeira com a imagem do santo protetor. Seguem-se cortejos, procissões e missas até o encerramento da festa com o descimento dos mastros.

As festas são movimentadas por grupos de dançadores e/ou instrumentistas chamados guardas, ternos ou cortes. Dispostas em duas fileiras paralelas tendo a frente uma bandeira com a imagem do santo protetor (Figuras 1 e 2), as guardas são conduzidas por um capitão (Figuras 3 e 4), que tem a missão de zelar espiritualmente pelo grupo e também de entoar as cantigas cujo refrão será repetido pelos demais componentes. É comum que as guardas tenham mais de um capitão, formando a chamada linha de capitães, a fim de que se revezem nas cantigas.
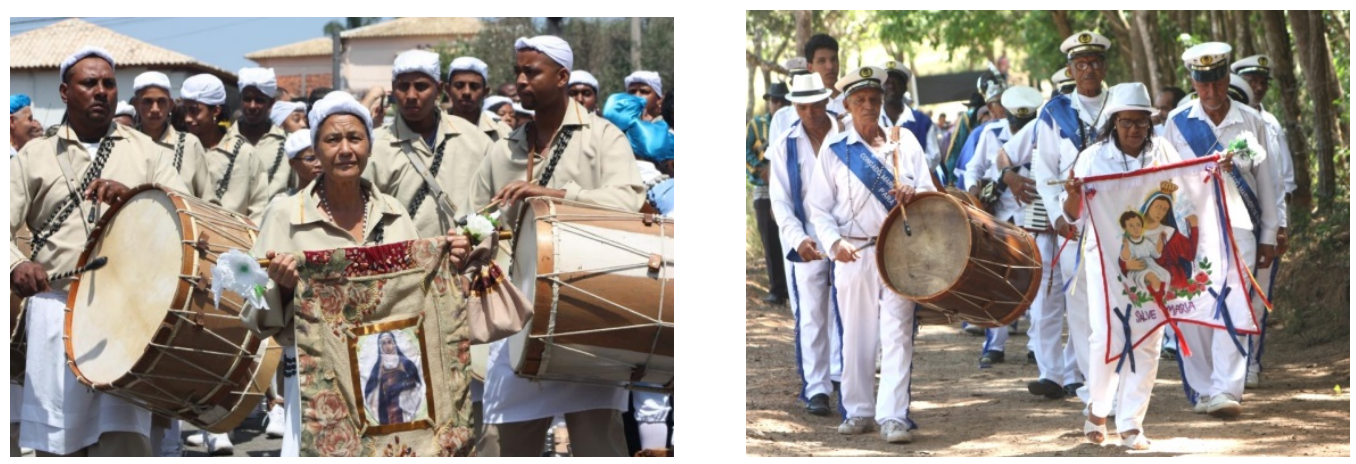

Figuras 1 e 2. Guardas de reinado (moçambique à esquerda e congo à direita) com suas respectivas bandeiras.

Fonte. Acervo pessoal do autor. 

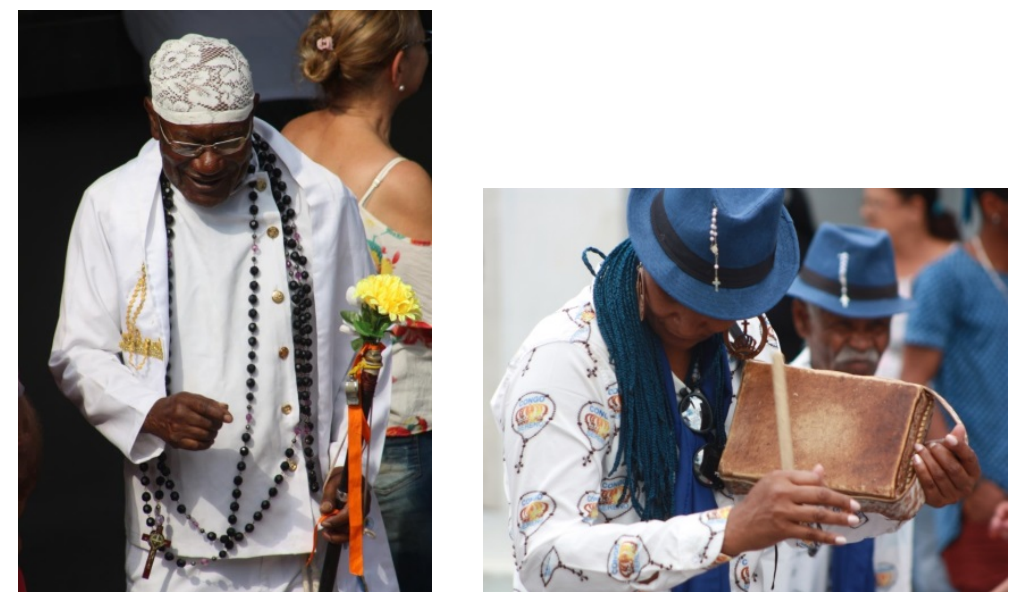

Figuras 3 e 4. Capitão do terno de moçambique (esquerda) e capitã de congo (direita). Fonte. Acervo pessoal do autor.

No universo do reinado, o capitão, ou capitã, é escolhido(a), entre outros motivos, por sua capacidade de entoar cânticos com rimas improvisadas e também de guardar de memória aqueles versos transmitidos oralmente de geração em geração que trazem um conjunto de saberes partilhados e traduzem vivências ancestrais do grupo. Tendo conteúdo metafórico, tais versos proporcionam diversão durante a festa, mas também trazem formas de proteção espiritual e de manutenção de um saber coletivo, pela qual cabe aos capitães zelar.

A festa de reinado, dado o componente africano presente em sua origem, também guarda muito das tradições da etnia banto, da África ocidental. Muitos membros dessa etnia vieram para o Brasil na condição de escravos (RIOS, 2006, p. 27), mas a escravidão não eliminou esses traços culturais que, transmitidos oralmente, foram sendo reelaborados à medida que entravam em contato com o cristianismo.

Uma característica da religiosidade banto no congado é a divisão do mundo em um plano físico, povoado pelos vivos, mas sujeito a intervenções de forças ruins contra as quais se deve buscar proteção, e um plano espiritual, "composto pelas almas dos ancestrais e espíritos diversos, próximo do universo dos vivos com os quais mantém relações fastas ou nefastas" (RIOS, 2006, p. 28). Ainda de acordo com Rios (2006), esse contato com o mundo sobrenatural é um dom de certos líderes capazes de conduzir rituais mágicos, atuando em benefício da comunidade.

Essa concepção, proveniente da cultura banto, se mostrou coerente com a concepção cristã de um mundo dividido entre o espiritual e o material e também na relação entre seres físicos e entes espirituais. A própria igreja católica no Brasil, depois da abolição da escravatura, incorporou muito dessas crenças e rituais, adaptando-os em uma liturgia que deu origem ao catolicismo negro: aquele que incorpora resquícios de tradições africanas e que se encontra presente, sobremaneira, nas festas de reinado.

A relação entre o mundo espiritual e o físico muitas vezes se dá através de cânticos que veiculam formas de proteção espiritual e também ensinamentos alusivos à manutenção dessas fórmulas. O mundo do reinado é perpassado tanto pelo maligno quanto pelo benigno, razão pela qual é preciso recorrer a essas, diríamos, palavras 
mágicas. Enunciados construídos com o efeito de serem ancestrais e universais, não sendo enunciados por um, mas por todos os congadeiros.

O levantamento bibliográfico realizado por esta pesquisa evidencia que estudos sobre cantigas afrodescendentes em festividades populares, como o de Rios (2006) e Silva ([2015] 2020), ainda são escassos. A relação com o universo religioso sincrético é uma constante dessas cantigas e em sua estrutura é possível apontar o refrão como uma espécie de célula mágica que encerra um significado cifrado:

a música congadeira apresenta uma complexa cadeia de significados em sua estrutura e em seus processos de produção. Muitos dos versos, por exemplo, são ricos em metáforas: um recurso criativo que remonta aos tempos de escravidão, utilizado para proteger a essência dos cânticos religiosos e promover a comunicação interna. (COMUNIDADE DOS ARTUROS; LUCAS; LUZ, 2006, p. 32)

Como lembra-nos Garone ([2008] 2020, p. 155-6), "músicas e cantigas (...) não são considerados como de 'autoria' dos congadeiros, se definindo antes como parte de um acervo ancestral e imemorial, quando muito 'relevadas [sic] do alto', através de sonhos, visagens, intuições, e incorporadas ao repertório tradicional". A propósito, como afirma a autora, essas cantigas também perpassam o sobrenatural, ao qual se credita sua origem:

todos os cantos e versos do congado possuem propriedades mágicoreligiosas (...). Puxar um canto no congado implica um estado de transe místico em que a música a ser cantada é descrita como chegando do 'alto', isto é, fruto de uma comunicação do puxador com os santos e entidades do congado. (GARONE, [2008] 2020, p. 161)

Essas cantigas, por sua vez, embora tenham temas muito diversos e ocasionalmente, através de versos improvisados, retratem episódios ocorridos durante a festividade, também podem ser organizadas segundo eixos temáticos, como a escravidão e as relações entre dominantes e dominados; os simbolismos africanos; os preceitos morais e os valores coletivos e as formas de proteção espiritual.

A mensagem trazida pelas cantigas traz elementos que aludem a um conjunto de saberes coletivos que fortalece a identidade do grupo. Assim, "o canto para os congadeiros possui um papel importante, é um caminho de conhecimento e de ensinamentos" (SILVA, [2015] 2020, p. 70). Esse ensinamento, por sua vez, envolve a estetização construída no e pelos versos das cantigas. Desse modo, Silva ([2015] 2020) aponta a relação entre esse conhecimento tradicional e sua presença estetizada em cantigas:

O conhecimento gerado pelos traços artísticos que estão presentes no Congado, ao ganhar espaço no processo grupal, torna-se um saber daquele grupo de participantes, ganhando espaço na história e na memória coletiva do grupo e, assim, assumindo um papel significativo na formação humana. (SILVA, [2015] 2020, p. 68)

Desse modo, observa-se que essas cantigas são um traço cultural que se volta para os próprios congadeiros, resguardando sua identidade. Uma vez feita essa exploração 
preliminar, vejamos essas cantigas, agora à luz da Análise do Discurso pelo referencial teórico-metodológico apresentado.

\section{ANÁLISE DO CORPUS}

Iniciamos esta análise pela abordagem de aspectos enunciativos, os quais fundamentam a construção do sentido nas generalizações discursivas presentes nas cantigas selecionadas para este trabalho. Nesse caso, precisamos verificar o papel das competências linguageiras e dos sujeitos no quadro comunicacional de Charaudeau ([2006] 2020, 2008). Em relação às competências, cabe enfatizar que o universo do reinado é um espaço de produção do discurso no qual cabe aos sujeitos reconhecerem a situação de troca comunicacional, e enunciar em conformidade com ela através de uma partilha de saberes que nortearão a troca comunicacional e os sentidos desse discurso.

Os sujeitos demonstram sua competência situacional (cf. CHARAUDEAU, [2006] 2020, p. 2) através da representação que fazem de si face àquela situação de comunicação, que envolve objetivos e também um conteúdo dessa troca, como nos mostram as cantigas seguintes. Nelas o congadeiro fala um pouco de sua história de vida e de seu papel na festa de reinado. A identidade e o fazer enunciativos do congadeiro na festa são relacionados a uma história de sofrimento e de uma devoção a Senhora do Rosário, para a qual o congadeiro deve trabalhar:

Eu nasci aqui no mundo

Eu nasci pra trabalhar

Hoje eu trabalho é com Deus

C’a Virgem Mãe do Rosário ${ }^{10}$

(ARRI, 2006, CD 1, Faixa 14, 2m54s)

Nos versos citados, trabalhar significa, no linguajar do congado, executar cantos e danças, conduzindo a guarda para suas funções. Já nos versos seguintes, o capitão enfatiza seu passado de sofrimento, com o qual os congadeiros se identificam, já que esse sofrimento remete à escravidão. Mas o congadeiro se coloca no discurso não apenas com devoção pelo divino, mas com afeto pela população:

Inté pouco eu fui criança

Eu também fui sofredor

Vou fazer festa pro povo

Com carinho e muito amor.

(ARRI, 2006, CD 1, Faixa 5, 1m58s)

Ao mobilizar esses signos (sofredor, trabalhar, fazer festa), o congadeiro mostra seu papel na coletividade a partir de um imaginário sociocultural que aborda o passado escravo, a libertação e sua responsabilidade em promover a festa de congado. $O$ congadeiro, assim, herda, por um conjunto de saberes transmitido pelo discurso, uma representação de si e de seus interlocutores e também os sentidos dados aos cânticos. Sentidos que seriam construídos pelas divindades do congado ou pela tradição oral.

\footnotetext{
${ }^{10}$ Aqui como em outras citações do corpus, conforme informado na introdução do artigo, frisamos que as letras foram copiadas do encarte do CD duplo Reinado do Rosário de Itapecerica: da festa e dos mistérios.
} 
A essa representação de si no discurso do congado apresentamos a seguir no esquema comunicacional de Charaudeau (2008):

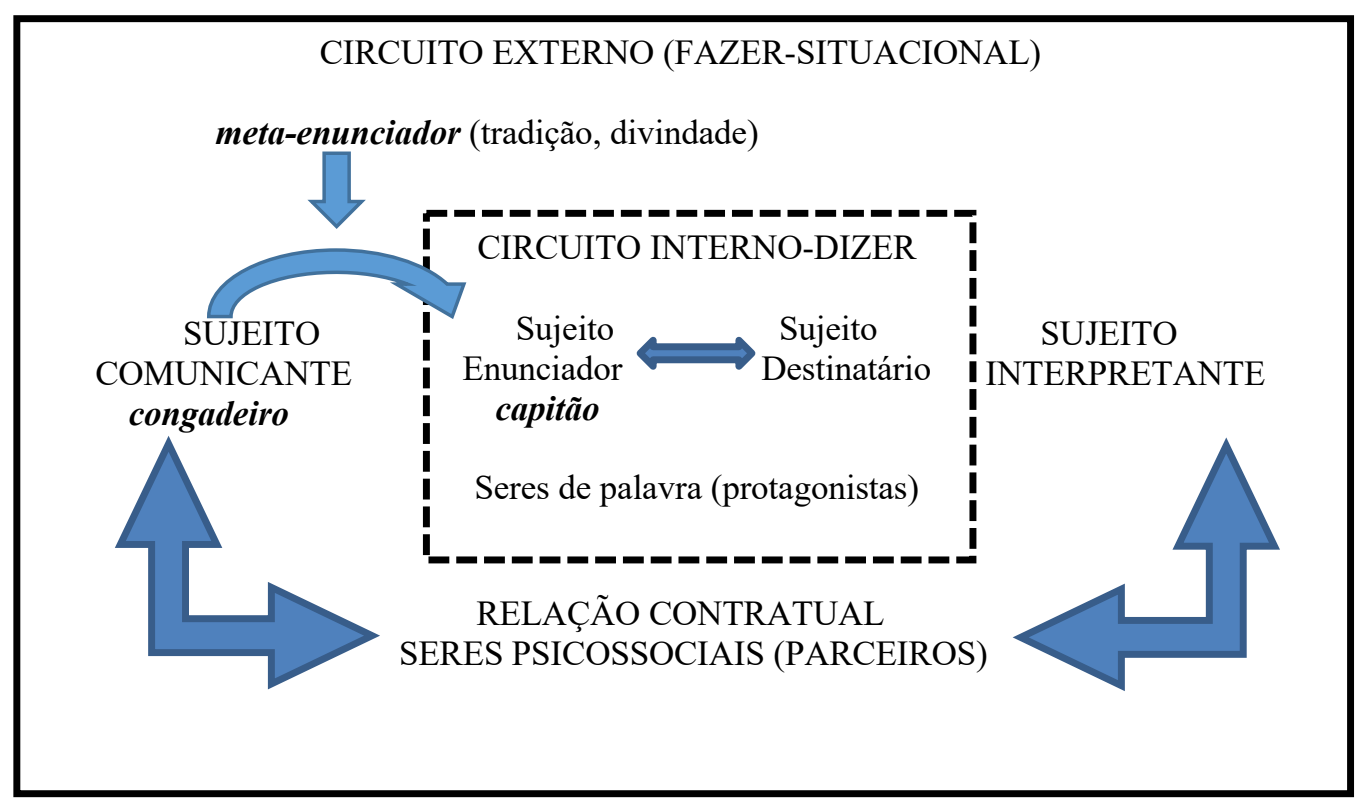

Esquema 3. A enunciação nas cantigas de congado.

Fonte. Adaptado de Charaudeau (2008, p. 21).

No esquema anterior, o Sujeito Comunicante Congadeiro é um papel mais amplo dentro da festa, já que ele pode enunciar como bandeireiro, dançador, caixeiro (tocador de caixa ou tambor), capitão-mor (que atua na organização da festa). A partir desse papel, o Sujeito Comunicante se desdobra, na e pela enunciação, no Sujeito Enunciador Capitão, sobre o qual recai a responsabilidade de conduzir a guarda e executar os cânticos. Ao desdobrar-se em Sujeito Enunciador Capitão, o congadeiro recorre a estratégias de legitimidade e de credibilidade.

Uma primeira estratégia de legitimação é desdobramento que o Sujeito Comunicante opera em Sujeito Enunciador Capitão, legitimando seu papel e sua autoridade na festa como portador de um saber que lhe é garantido pela tradição e/ou pelas divindades do congado, como Nossa Senhora do Rosário. Já a estratégia de credibilidade, se manifesta pela mobilização de um meta-enunciador (tradição/divindade), ao qual se credita a origem dos enunciados do capitão, como nos mostra o depoimento seguinte: "Eu digo pros meus companheiros que a gente sempre tem uma luz lá de cima, a Nossa Senhora. Então quando a gente tá cantando, ela ilumina o espírito da gente, a gente canta coisa que no outro dia você não sabe o que cê cantou" (CAPITÃO GERALDO D'ALESSANDRO apud RIOS, 2006, p. 33).

A intervenção do divino se confunde com a intercessão dos congadeiros já falecidos a quem se atribuem tanto os versos quanto a própria voz do cantador: "quando eu tô cantando assim, minha voz mudou. A voz minha passou a ser a do meu pai. Ele desceu fardadinho, de capitão e bateu no meu ombro" (CAPITÃO GERALDO D'ALESSANDRO apud RIOS, 2006, p. 32). O Sujeito Enunciador Capitão, ao colocarse em posição de quem se encontra "a serviço de" (grifo nosso), e de quem executa um cântico de um repertório de saberes coletivos, realça a posição de neutralidade enunciativa 
de quem está a serviço de uma divindade ou da tradição, reforçando o efeito de verdade do enunciado, como nos mostra a cantiga a seguir:

Eu canto neste reinado

Não é por causa da festa

Ajudar os meus irmãos

Pagar sua promessa

(ARRI, 2006, CD 1, Faixa 8, 2m58s)

Nesses versos, o Sujeito Capitão enuncia que o essencial não é promover diversão (festa), mas auxiliar aqueles participantes da festa que têm débito com o divino na forma de uma promessa aos santos. A relação da festa com o divino e/ou com a tradição, que funcionam como instâncias meta-enunciativas, pode ser ilustrada com a cantiga seguinte, a qual relaciona a origem da festa com a origem do mundo:

De joelho eu caio n'água

De joelho eu vou fundo

Essa festa de Maria

É do princípio do mundo

(ARRI, 2006, CD 1, Faixa 1, 2m27s)

Uma vez verificados os aspectos enunciativos dessas generalizações, vejamos como elas ocorrem segundo os eixos temáticos apresentados anteriormente, a começar pelo tema da escravidão, que, muitas vezes, retrata, metaforicamente, a sobrevivência dos dominados em um contexto de opressão:

Eu joguei meu patinho na lagoa

Para ver meu patinho nadar

Veio o velho caçador atirou, não matou,

Meu patinho na lagoa ficou

(ARRI, 2006, CD 1, Faixa 8, 2m56s)

O conteúdo alegórico da generalização contida na cantiga anterior funciona de maneira semelhante ao da fábula. No caso, o Sujeito Enunciador traz o discurso sobre a luta pela liberdade, metaforizada pelo "patinho na lagoa" que sobrevive aos tiros do caçador, sentido que é partilhado pelo grupo e cuja origem é atribuída à tradição. Já na cantiga seguinte, o capitão enuncia a devoção dos escravos por Nossa Senhora (do Rosário):

No tempo do cativeiro

Quando o sinhô me batia

Eu grita pra/por Nossa Senhora, ai meu Deus

Como a pancada doía

(ARRI, 2006, CD 1, Faixa 13, 3m15s)

Por meio desses versos, resgata-se a tradição devocional com Nossa Senhora do Rosário de modo a estabelecer um vínculo com o divino. Esse resgate meta-enunciativo de uma memória ancestral traz ainda a presença de elementos africanos dados, por exemplo, pela recorrência de palavras, ou de versos inteiros, de origem banto (RIOS, 
2006). Através desses versos, transcritos a seguir, o Sujeito Enunciador Capitão reafirma sua ligação com o divino e com sua ancestralidade africana, ao enunciar que:

\author{
eu prendeu falar língua \\ mamãe é criola \\ língua de rebolo ${ }^{11}$ \\ mamãe é criola
}

(ARRI, 2006, CD 2, Faixa 16, 11m8s)

Falar língua, no linguajar do congado, significa cantar através de versos ditados pela divindade: a jomba. Essa habilidade, exercida pelos capitães, requer também uma aprendizagem, a qual é dada pela vivência da tradição e pela inspiração da divindade:

Óia minha jomba num vai reparar

Sou menino novo aprendendo a falar

(ARRI, 2006, CD 2, Faixa 17, 2m40s) (grifo nosso)

A divindade como instância meta-enunciativa da generalização é uma estratégia que também se apresenta nos versos seguintes, por exemplo, construídos com palavras de origem africana e que remetem a uma fórmula de proteção espiritual cujo sentido não é revelado pelo Sujeito Enunciador Capitão:

Tempera com sangue de nena numa beira de nena ocaia no injó de

[cafom de vindero

Ô que mora num injó de vindero

Tempera com sangue de nena num injó de jequê

Mandou um orira num injó de jequê

(ARRI, 2006, CD 2, Faixa 16, 2m40s) (grifos nossos)

A generalização sobre o elemento africano nas cantigas se manifesta também pela alusão que o Sujeito Enunciador Capitão faz ao dendê, que, segundo Cascudo (1984, p. 285), nas culturas banto e ioruba, representa o sangue africano, o que reforça o vínculo da festa com a ancestralidade africana:

\author{
Nessa festa do Rosário tem dendê-ê-ê \\ Tem dendê-ê-ê \\ Tem dendê-ê-ê \\ Nessa festa do Rosário tem dendê-ê-ê \\ Tem dendê-ê-ê \\ Tem dendê-ê-ê \\ (ARRI, 2006, CD 2, Faixa 5, 2m43s) (grifos nossos)
}

No caso, recorrer à tradição para enunciar reforça o efeito de meta-enunciação, já que o Sujeito Enunciador Capitão recorre à voz de antepassados, voz diluída na tradição oral, que dá a esse discurso o efeito de ser enunciado por todos e não individualmente pelo capitão, que apenas repete um enunciado generalizado.

Outro eixo temático dessas cantigas é o dos preceitos morais, transmitidos através de generalizações discursivas que comunicam "o cuidado com o outro e as preocupações

${ }^{11}$ Rebolo é uma etnia africana presente no atual território do Congo e de Angola, sendo que muitos dos seus membros foram os primeiros a serem trazidos como escravos para o Brasil. 
com os membros do grupo" (SILVA, [2015] 2020, p. 60), versando, por exemplo, sobre a transmissão de experiências dos mais velhos para os mais jovens, como se observa na cantiga a seguir, em que passar pela tábua (tauba) metaforiza a passagem por uma experiência vivida ${ }^{12}$. Experiência que o Sujeito Enunciador Capitão comunica ao grupo reafirmando o valor da experiência vivida como fonte de saber:

\author{
Olha a tauba que passa ocê \\ Passou eu, passou eu \\ Olha a tauba que passa ocê \\ Passou eu, passou eu \\ (ARRI, 2006, CD 2, Faixa 12, 3m8s)
}

Através dessa generalização, o Sujeito Enunciador Capitão, mostrando o domínio de sua competência situacional, expressa sua responsabilidade na comunicação de preceitos moralizantes. Assim, segundo Silva ([2015] 2020, p. 62), o zelo pelo outro se manifesta "no trabalho exercido pelos capitães de terno". Através de estratégias de legitimação e credibilidade, o Sujeito Enunciador Capitão assume uma posição de autoridade e de credibilidade, recorrendo a um enunciado legado pela tradição, a qual funciona, pela generalização, como instância enunciativa coletivizada.

Outras generalizações, por sua vez, reforçam a solidariedade aos participantes da festa, aos quais cabe ao capitão proteger. Entre esses participantes, citam-se os reis e rainhas, que as guardas devem conduzir em procissão durante a festa. Os versos seguintes, no caso, são entoados, para oferecer proteção e mostram, mais que uma subserviência, o respeito e o zelo pelos outros membros do grupo:

\author{
Me dá a mão \\ Que eu te passo na pinguela \\ A pinguela é de imbaúba \\ Pode ter caruncho nela \\ (ARRI, 2006, CD 1, Faixa 14, 2m54s)
}

A pinguela metaforiza a travessia feita pelo cortejo em que rei, rainha, príncipe e princesa são conduzidos. No cortejo também estão presentes as forças do maligno e do sagrado (MAGALHÃES, 2006; RIOS, 2006), razão pela qual cabe ao Sujeito Enunciador Capitão proteger, com cânticos, os participantes-mores da festa: o rei e a rainha. Já a imbaúba é uma árvore de madeira leve e frágil, usada na construção de pinguelas em pequenos cursos d'água. Apesar de versátil, a imbaúba também é um material frágil, resultando na necessidade de se alertar para a proteção daquele(a) que o terno de reinado conduz.

Outros versos também são evocados em situações de rua com o fim de evitarem brigas, o que se justifica pelo fato de a festa ocorrer em espaços públicos, ruas e praças, envolvendo aglomerações de pessoas e venda de bebidas alcoólicas. A certos versos, como os que se seguem (RIOS, 2006), são atribuídas propriedades de evitar brigas e confusões durante a passagem dos ternos:

\footnotetext{
${ }^{12}$ Era pela tábua (ou estiva), por exemplo, que os negros embarcavam e/ou desembarcavam nos navios negreiros.
} 


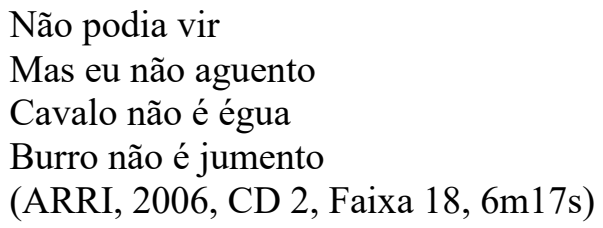

No caso, a proteção que é mobilizada pelo Sujeito Enunciador Capitão não se estende apenas aos próprios congadeiros, mas aos demais presentes, o que mostra o cuidado não apenas com os participantes, mas com o evento em si. De modo que reforçase, nessas generalizações, o valor moral de zelar pelo outro, seja ele ou não um congadeiro. Moralidade e proteção, assim, se confundem nessas generalizações.

Pedidos de proteção são constantes nessas generalizações, que também obedecem à ocasião de serem entoadas, como o momento em que ela se reúne e são feitas rezas e cânticos a fim de garantir a proteção do grupo. Essas generalizações não são enunciadas em espaços públicos, mas em locais reservados e solenes. As generalizações de proteção espiritual têm o aspecto de fórmulas mágicas, dadas por enunciados transmitidos de geração em geração, e essa transmissão oral realça a importância da meta-enunciação, centrada na instância do divino ou da tradição.

Essa proteção espiritual dada pelas generalizações se justifica porque, segundo os congadeiros, ocorrem "as más influências, o ciúme, e as invejas que reina muito no congado. Porque o reinado, dizia meu pai, reina o bem e reina o mal" (CAPITÃO D'ALESANDRO apud MAGALHÃES, 2006). Enunciar segundo manda a tradição, nesse caso, significa "uma subida em direção ao passado" (CHARAUDEAU, 2006, p. 213), na qual o grupo encontra suas origens ou o próprio sagrado, a partir do qual enunciam consolidando o efeito de generalização discursiva, pela qual "o grupo encontra os ancestrais, descobre sua voz e a recebe como herança, sente-se depositário dessa voz" (CHARAUDEAU, 2006, p. 213). Os versos a seguir ilustram um momento desse rito inicial de proteção. São evocadas as divindades máximas do cristianismo e também aquelas identificadas com a festa do congado, no caso, São Benedito:

\author{
Nas horas de Deus começa \\ O Pai e Filho e Espírito Santo \\ Mas vou pedir Nossa Senhora \\ Que livra nós dos maus encantos \\ Nas horas de Deus começa \\ Nas horas de Deus amém \\ Vou pedir São Benedito \\ Que livra nós do mal que envém \\ (ARRI, 2006, CD 2, Faixa 10, 4m32s)
}

Observa-se o sincretismo entre a evocação de Nossa Senhora contra "maus encantos" (grifo nosso), ou feitiços, comuns na religiosidade afro-descendente. São Benedito aparece de forma recorrente como aquele que fecha o corpo (protege contra malefícios físicos) dos congadeiros. E recorrer ao santo é tarefa que cabe ao Sujeito Enunciador Capitão, que é o sujeito legitimado e credibilizado a conduzir, através de versos que atuam como proteção contra malefícios físicos, a prática enunciativa contra o que os congadeiros definem como "o mal": 


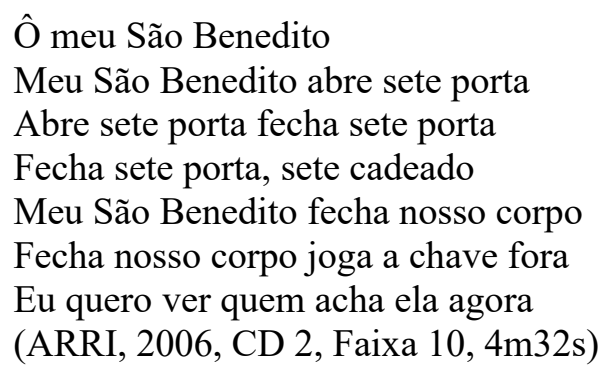

Novamente a generalização discursiva se constrói a partir do meta-enunciador dado pelo sagrado e/ou tradição, que legitima e credibiliza o discurso do capitão dando ao enunciado o sentido de um existir sempre.

Durante a festa ocorrem cortejos, quando a guarda se dirige, por exemplo, para visitar a igreja, para buscar o rei e a rainha, para saudar os mastros sagrados. Nesse trajeto, o grupo passa por esquinas (na cidade) ou encruzilhadas (em áreas rurais), considerados na tradição do reinado como lugares perigosos, dado o entrecruzamento de forças malignas e benignas. Nesses locais, além de realizar uma coreografia para limpar o cruzamento, são enunciadas pelo Sujeito Capitão generalizações voltadas à proteção do grupo:

\author{
Andei, andei, andei lá no mar \\ Procurei agulha achei foi dedal \\ O poço tá cheio eu tiro com a cuia \\ Se a cuia quebrar eu costuro com agulha \\ (ARRI, 2006, CD 2, Faixa 17, 2m40s)
}

$\mathrm{Na}$ cantiga anterior, o sentido metafórico se ressalta mostrando a complexidade de significados nessas generalizações: a agulha remete àquilo que fere enquanto que o dedal é o que protege (RIOS, 2006, p. 30). Já tirar a água do poço que está cheio se refere à limpeza espiritual do ambiente, ao mesmo tempo em que mostra como o objeto que fere, a agulha, também pode estar a serviço de uma causa benéfica ao grupo, costurar a cuia com a qual se limpa o ambiente.

\title{
CONSIDERAÇÕES FINAIS
}

Ao longo deste artigo, e com a abordagem de um corpus organizado em quatro temas, escravidão, ancestralidade africana, moralidade e proteção espiritual, buscamos mostrar como as generalizações discursivas são construídas: a escolha de um metaenunciador pode determinar a credibilidade e a legitimidade do Sujeito Comunicante e do Enunciador. Essa legitimação e credibilização ocorrem através da outorga a uma divindade e/ou a uma tradição da origem daquele enunciado, o que leva à construção de um efeito de verdade universal.

Ao fim desta discussão atentamos para o fato de que essas generalizações se constituem a partir da tradição oral, sendo elas, também, um conjunto de saberes que o grupo busca preservar. Nesse caso, as generalizações discursivas não são apenas fórmulas linguísticas que traduzem crenças e saberes partilhados, mas um patrimônio imaterial que resguarda a identidade do grupo. No caso, essas análises não visam apenas desmantelar o funcionamento dessas generalizações, nem dissecar os sentidos possíveis desses 
discursos, como uma forma de mostrar as crenças por trás dos efeitos de verdade. As análises nos mostram, segundo esperamos, como diversos grupos apresentam diferentes maneiras de representar e manter sua identidade por meio daquilo que enunciam e de como o enunciam.

A generalização discursiva permite que o discurso dado pela tradição oral se sustente graças a uma, diríamos, distribuição de responsabilidades enunciativas. Legar o enunciado a um outro é também garantir a essa enunciação uma aura de respeitabilidade. Enunciação a qual se deve recorrer justamente para que esses sujeitos legitimem seu discurso e se invistam com a devida credibilidade para exercer o papel que lhes determina a tradição. Assim, ao recorrer à meta-enunciação, o discurso oral se legitima, se sustenta e se perpetua, sendo, por outra via, continuamente revisitado e re-enunciado como um patrimônio de memória.

Como uma manifestação religiosa-cultural afrodescendente, as festividades de congado com todo seu conjunto semiótico que inclui suas cantigas, sua musicalidade, seu gestual, sobrevivem graças à atuação conjunta da comunidade com capitães e congadeiros que transmitem de geração em geração seu conhecimento. Essa memória, ao que parece, permite que a tradição oral das generalizações presentes nas cantigas de congado sobreviva de maneira pujante. São esses mesmos sujeitos que permitem que chegue até nós os traços dessa cultura ainda pouco conhecida em uma sociedade cada vez mais perpassada pela cultura midiática. E essa é a contribuição que se espera ter dado com este artigo.

\section{REFERÊNCIAS}

ALI-BOUACHA, A. La question genérique: statut linguistique et enjeu discursif. In: MOIRAND, S.; ALI-BOUACHA, A.; BEACCO, J-C. (Orgs). Parcours linguistiques de discours spécialisés. Berne: Peter Lang, 1993. pp. 279-289.

ALI-BOUACHA, A. Enonciation argumentation et discours: le cas de la généralisation. SEMEN, Université de Franche-Comté, Franche-Comté, Presses Universitaires de Franche-Comté, 8, pp. 1-15, 2007. Disponível em <http://semen.revues.org/3985>; acesso em 03 jul. 2020.

ASSOCIAÇÃO DO REINADO DO ROSÁRIO DE ITAPECERICA (ARRI). Reinado do Rosário de Itapecerica: da festa e dos Mistérios. Itapecerica: ARRI/Viola Correa Produções Artísticas, 2006. 2 CDs. Acompanha livreto.

CASCUDO, Luís da Câmara. Dicionário do Folclore Brasileiro. 5. ed. Belo Horizonte: Itatiaia, 1984.

CHABROL, Claude. Le tiers du discours dans l'espace idéologique. In: CHARAUDEAU, Patrick; MONTES, Rosa (Orgs). La voix cachée du tiers: des nondits du discours. Paris: L`Harmattan, 2004. pp. 43-52.

CHARAUDEAU, Patrick. Langage et discours. Paris: Hachette, 1983.

CHARAUDEAU, Patrick. De la compétence sociale de la communication aux compétences de discours. In: Actes du colloque de Louvain-la-Neuve sur Compétence et didactique des langues, 2000. Disponível em <http://www.patrickcharaudeau.com/De-la-competence-sociale-de.html>; acesso em 15 abr. 2020a. 
CHARAUDEAU, Patrick. Legitimação. In: CHARAUDEAU, P.; MAINGUENEAU, D. (Orgs). Dicionário de Análise do Discurso. Coordenação da tradução por Fabiana Komesu. São Paulo: Contexto, 2004a. p. 295.

CHARAUDEAU, Patrick. Credibilidade. In: CHARAUDEAU, P.; MAINGUENEAU, D. (Orgs). Dicionário de Análise do Discurso. Coordenação da tradução por Fabiana Komesu. São Paulo: Contexto, 2004b. p. 143.

CHARAUDEAU, Patrick. Identité sociale et identité discursive: un jeu de miroir fondateur de l'activité langagière. In: CHARAUDEAU, P. (Org.). Identités sociales et discursives du sujet parlant. Paris: L`Harmattan, 2005a. pp. 55-89.

CHARAUDEAU, Patrick. La voix cachée du tiers: des non-dits du discours. Paris: L'Harmattan, 2005b.

CHARAUDEAU, Patrick. Discurso político. Tradução de Dílson F. da Cruz e Fabiana Komesu. São Paulo: Contexto, 2006.

CHARAUDEAU, Patrick. Identités sociales, identités culturelles et compétences. In: Hommage a Paul Miclau (Références à compléter). S. 1.: s. e, 2006. p. 1-7. Disponível $\mathrm{em}<\mathrm{http}: / /$ www.patrick-charaudeau.com/Identites-sociales-identites.html $>$; acesso em: 08 jul. 2020 b.

CHARAUDEAU, Patrick. Uma teoria dos sujeitos da linguagem. In: LARA, G. M. P.; MACHADO, I. L. ; EMEDIATO, W. (Orgs.) Análises do Discurso Hoje, Volume 1. Tradução de Wander Emediato. Rio de Janeiro: Nova Fronteira/Lucerna, 2008. pp. 1130 .

COMUNIDADE DOS ARTUROS; LUCAS, G.; LUZ, J. B da. Cantando e Reinando com os Arturos. Belo Horizonte: Rona, 2006.

GARONE, Taís Diniz. Uma poética de mediação: história, mito e ritual no congado setelagoano - MG. Dissertação. Mestrado em Antropologia Social. Instituto de Ciências Sociais, Universidade de Brasília, Brasília, DF, 2008. Disponível em $<$ https://repositorio.unb.br/bitstream/10482/5564/1/2008_TaisDinizGarone.pdf >; acesso em 05 jul. 2020.

MAGALHÃES, Marcos. As Gerais dos congadeiros. In: ASSOCIAÇÃO DO REINADO DO ROSÁRIO DE ITAPECERICA (ARRI) (Org). Reinado do Rosário de Itapecerica: da festa e dos mistérios. Itapecerica: ARRI, 2006. pp. 11-24.

MAINGUENEAU, Dominique. Polifonia e cena de enunciação na pregação religiosa. In: LARA, G. M. P.; MACHADO, I. L. ; EMEDIATO, W. (Orgs.) Análises do Discurso Hoje, Volume 1. Tradução de G. M. P. Lara, A. S. Chaves e I. D. Machado. Rio de Janeiro: Nova Fronteira/Lucerna, 2008. pp. 199-218.

MAINGUENEAU, Dominique. O poeta e camponês: o impossível ponto de vista do dominado. In: LARA, G. P.; LIMBERTI, R. P. (Orgs). Discurso e (des)igualdade social. São Paulo: Contexto, 2015. pp. 95-108.

RIOS, Sebastião. Os cantos do Rosário. In: ASSOCIAÇÃO DO REINADO DO ROSÁRIO DE ITAPECERICA (Org). Reinado do Rosário de Itapecerica: da festa e dos mistérios. Itapecerica: ARRI, 2006. pp. 27-39.

MOIRAND, S. Une grammaire du texte et des dialogues. Paris: Hachette, 1990.

PEREIRA, Edimilson de Almeida; GOMES, Núbia Pereira de Magalhães. Os Arturos: Negras Raízes Mineiras. 2 ed. Belo Horizonte: Mazza, 2000.

SILVA, Aline Ribeiro da. Os contos da memória nas contas do rosário: a formação cultural meio à festa de Nossa Senhora do Rosário em Oliveira/MG. Dissertação. Mestrado em Psicologia. Universidade Federal de São João Del-Rei, São João Del Rei, MG, 2015. Disponível em $\quad<$ https://ufsj.edu.br/portal2- 
repositorio/file/mestradopsicologia/2016/defesas site/disseratacao aline.pdf $>$; acesso em: 06 jul. 2020.

Artigo recebido em: set. de 2020 .

Aprovado e revisado em: nov. de 2020.

Publicado em: dez. de 2020.

Para citar este texto:

MORATO, Elisson Ferreira. Generalização Discursiva e Enunciação nas Cantigas de Congado em Minas Gerais: uma abordagem semiolinguística. Entremeios [Revista de Estudos do Discurso, ISSN 2179-3514, on-line, www.entremeios.inf.br], Seção Temática, Programa de PósGraduação em Ciências da Linguagem (PPGCL), Universidade do Vale do Sapucaí (UNIVÁS), Pouso Alegre (MG), vol. 22, p. 236-254, jul. - dez. 2020.

DOI: http://dx.doi.org/10.20337/ISSN2179-3514revistaENTREMEIOSvol22pagina236a254 